\title{
Thermal Performance of Ionic Liquids for Solar Thermal Applications
}

\author{
Titan C. Paul, A.K.M. M. Morshed, Elise B. Fox ${ }^{1}$, Ann E. Visser ${ }^{1}$, Nicholas J. Bridges ${ }^{1}$, Jamil A. Khan \\ Department of Mechanical Engineering \\ University of South Carolina, Columbia, SC, USA \\ ${ }^{1}$ Savannah River National Laboratory, Aiken, SC, USA
}

\begin{abstract}
Experimental investigations were carried out to evaluate thermophysical properties, i.e.density, viscosity, heat capacity, and thermal conductivity and high temperature forced convection behavior of N-butyl-N,N,N-trimetylammoniumbis(trifluormethylsulfonyl)imide $\left(\left[\mathrm{N}_{4111}\right]\left[\mathrm{NTf}_{2}\right]\right)$ ionic liquid (IL) for its potential application in concentrated solar power (CSP). Results from the experiments will be useful in assessing the potential of using ILs for solar thermal collectors. Experimental results show that thethermal conductivity was slightly decrease with the increase of temperature; vary from 0.124 to $0.121 \mathrm{~W} / \mathrm{m}$.K for a change in temperature of $283-343 \mathrm{~K}$, strong temperature effect on the viscosity of IL was observed and maintain an exponential relationship with the temperature; heat capacity increases linearly with temperature measured from 298$618 \mathrm{~K}$. Forced convection performance of the IL was studied in a circular tube under both in laminar and turbulent conditions. Although the heat transfer coefficient of the IL was found to be lower compared to the De-Ionized (DI) water, its thermal stability and other attractive properties may make it a viable candidate for solar collector use. Our experimental results also established that Shah's equation and Gnielinski's equation can predict forced convection performance of IL for both the laminar region and turbulent region respectively.
\end{abstract}

Keywords: Ionic Liquid; Heat Capacity; Thermal Conductivity; Convective Heat Transfer Coefficient; Nusselt number; Reynolds number.

*Corresponding Author

Dr. Jamil A Khan

Department of Mechanical Engineering

University of South Carolina, Columbia, SC 29208

E-mail: khan@cec.sc.edu

Phone: 1-803-777-1578 


\section{INTRODUCTION}

Concentrating sunlight from a large area using mirrors or lenses is an effective means to utilize solar energy and potentially an inexpensive means to replace conventional natural gas or coal to produce steam for electricity generation [1]. In concentrating solar power (CSP) plants, solar energy is concentrated using mirrors and lenses and stored in a fluid; this stored energy is transferred to generate steam for electrical power generation. Working fluid used in the CSP plant plays the vital role and determines the overall efficiency of the system. Currently used working fluid have low to moderate thermal stability and low heat storage capacities that results in high operating costs [2], which necessitates the development of new energy-efficient working fluids. Energy-efficient working fluid should have high temperature thermal stability and high energy storage capability.

Ionic liquids (ILs)-a group of salts, which are liquid at ambient temperature (less than $100^{\circ} \mathrm{C}$ ) and are considered as the potential replacement of the currently used working fluid. [3-8]. ILs have severalexcellent physical and chemical properties including high thermal stability, negligible vapor pressure and volatility, exposure to air and moisture stability, low melting point, wide electrochemical window, nonflammability, high ionic conductivities, high solvating capability, corrosion resistance to plastics and carbon steels [9-18]. For those excellent properties, ILs become very useful in material processing [19], as a catalyst for synthesis of inorganic nano-materials [20], and as lubricants [21].

Due to its diverse potential applications, ILs arebeing investigated by a number of researchers to explore different perspective of the liquid; most of these researches have concentrated on the study of thermophysical properties; among those only a few numbers of study were concentrated on the study of thermal and transport properties [22-27]. To the best of the authors, no study has been reported yet on high temperature and turbulent heat transfer performance of this ILs. To assess effectiveness of ILs in CSP plants, conjugate study of thermophysical properties and high temperature heat transfer performance is necessary.

Here, we are reporting results of our experimental study on thermophysical property measurement and high temperature convective heat transfer study. N-butyl-N,N,Ntrimetylammoniumbis(trifluormethylsulfonyl)imide $\left(\left[\mathrm{N}_{4111}\right]\left[\mathrm{NTf}_{2}\right]\right)$ are chosen as the ionic liquid to study as it is the most common, commercially available and previously studied ionic liquid for thermophysical property, i.e.density, viscosity, thermal conductivity and heat capacity [27]. Heat 
capacity and thermal conductivity havebeen previously studied by H. Liu et al. [27] for the temperature range of $343-450 \mathrm{~K}$ and $284-314 \mathrm{~K}$ respectively. In our study, we conducted heat capacity, viscosity and thermal conductivity measurement in the range of 298-618 K, 293-363K, and 283-343K respectively along with forced convection study in a circular pipe in both laminar and turbulent regions. Heat capacity will indicate energy storage capacity of the ILs in CSP system, viscosity will indicate pumping power penalty for the ILs, thermal conductivity and forced convection performance indicate its performance inthe secondary heat exchanger. The results of this report are important for the comprehensive assessment of this ionic liquid and potential application in CSP plant.

\section{NOMENCLATURE}

$\begin{array}{lll}q^{\prime \prime} & \text { Heat flux } & {\left[\mathrm{W} / \mathrm{m}^{2}\right]} \\ Q & \text { Input power } & {[\mathrm{W}]} \\ V & \text { Voltage } & {[\mathrm{Volt}]} \\ I & \text { Current } & {[\mathrm{amp}]} \\ A_{h} & \text { Heating surface area } & {\left[\mathrm{m}^{2}\right]} \\ T & \text { Temperature } & {\left[{ }^{\circ} \mathrm{C}\right]} \\ x & \text { Axial distance } & {[\mathrm{m}]} \\ k & \text { Thermal conductivity } & {[\mathrm{W} / \mathrm{m} . \mathrm{K}]} \\ D_{o} & \text { Pipe outer diameter } & {[\mathrm{m}]} \\ L & \text { Heating length of test section } & {[\mathrm{m}]} \\ h(x) & \text { Local heat transfer coefficient } & {\left[\mathrm{W} / \mathrm{m}^{2} . \mathrm{K}\right]} \\ r & \text { Pipe radius } & {[\mathrm{m}]} \\ c_{p} & \text { Heat capacity } & {[\mathrm{J} / \mathrm{g} \cdot \mathrm{K}]} \\ V^{\prime} & \text { Volumetric flow rate } & {\left[\mathrm{m}^{3} / \mathrm{s}\right]} \\ f & \text { Friction factor } & {[\sim]}\end{array}$

\section{GREEK SYMBOLS}

$\mu \quad$ Dynamic viscosity $\quad$ [kg/s.m]

$\alpha \quad$ Thermal diffusivity $\quad\left[\mathrm{m}^{2} / \mathrm{s}\right]$ 
$v_{f} \quad$ Kinematic viscosity $\quad\left[\mathrm{m}^{2} / \mathrm{s}\right]$

$\rho \quad$ Liquid density $\quad\left[\mathrm{kg} / \mathrm{m}^{3}\right]$

\begin{tabular}{ll}
\multicolumn{2}{l}{ SUBSCRIPTS } \\
$f$ & Fluid \\
$w$ & Wall \\
$i$ & Inner \\
$s$ & Stainless Steel
\end{tabular}

\section{EXPERIMENTAL}

\subsection{Ionic Liquid}

99\% pure N-butyl-N,N,N-trimetylammoniumbis(trifluormethylsulfonyl)imide $\left(\left[\mathrm{N}_{4111}\right]\left[\mathrm{NTf}_{2}\right]\right) \mathrm{IL}$ was purchased from IoLiTecCompany, Germany. CAS (Chemical Abstracts Service) registry number is 258273-75-5. Molecular weight of $\left[\mathrm{N}_{4111}\right]\left[\mathrm{NTf}_{2}\right]$ is $396.37 \mathrm{~g} / \mathrm{mol}$. The chemical structure of the anion and cation and the molecular formula of the ionic liquid are as follows:

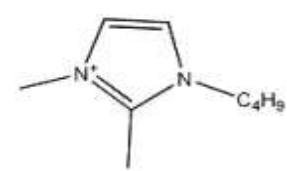

Cation

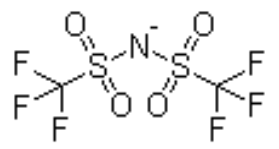

Anion

Molecular formula: $\mathrm{C}_{9} \mathrm{H}_{18} \mathrm{~F}_{6} \mathrm{~N}_{2} \mathrm{O}_{4} \mathrm{~S}_{2}$

\subsection{Thermophysical property measurement}

The density of ionic liquid was measured using a $1 \mathrm{~mL}$ Pycnometer from Thomas Scientific. The pycnometer and the sample were placed in a thermal bath (Thermo NESLAB) to maintain a constant temperature. The weight of the sample was measured by METTLER TOLEDO balance, which has a precision of $0.01 \mathrm{mg}$. Before using for IL, the pycnometer was calibrated with water. 
The density measurements were repeated at least three times at each temperature and the standard deviation of the measurement was $\pm 0.84 \%$.

The viscosity of the ionic liquid was measured using a cone and plate type rotary viscometer (LVDV-II+ProCP, from Brookfield Engineering Co.). The sample size of the cone and plate arrangement is $1 \mathrm{~mL}$. The cone and plate arrangement has a thermal jacket to maintain a constant sample temperature and it has the temperature accuracy within $\pm 0.1^{\circ} \mathrm{C}$. A thermal bath (Thermo NESLAB) was used to maintain constant temperature of the measuring sample. Temperature accuracy of the bath was within $\pm 0.01{ }^{\circ} \mathrm{C}$. The viscometer was calibrated using standard liquid (company provided). For each temperature three measurements were taken and the measurement standard deviation was estimated to be $\pm 3.2 \%$.

The heat capacity of the ionic liquid was measured using Differential Scanning Calorimetry (DSC Q2000 from TA instruments Inc.). The sample was placed in a standard aluminum hermetic pan covered with lid and the average sample size was $16.35 \mathrm{mg}$. Nitrogen was used as the cooling system at a flow rate of $40 \mathrm{~mL} / \mathrm{min}$. The DSC run was performed from 298.15$618.15 \mathrm{~K}$ at a heating rate of $10^{\circ} \mathrm{C} / \mathrm{min}$.

Thermal conductivity of the ionic liquid was measured by using the KD2 Pro thermal property analyzer (Decagon Device, USA). Measurement principle of this device is based on the transient hot wire method. The meter has a probe with $60 \mathrm{~mm}$ length and $1.3 \mathrm{~mm}$ diameter with a heating element and a thermoresistor, which is inserted vertically into the test sample. The probe is connected to a microcontroller for controlling and conducting the measurements. Before using for IL, the meter was calibrated with distilled water and standard glycerin. Thermal bath (Thermo NESLAB) was used to maintain a constant temperature of the measuring sample. For each measurement at least five readings were taken for each temperature and the standard deviation of the measurement has been calculated as $\pm 1.5 \%$.

\subsection{Convective heat transfer coefficient measurement}

\subsubsection{Experimental Setup}

Fig. 1 presents schematic of the flow loop used in this experiment. The loop consisted of a pump, test section, heat exchanger, storage tank, pressure transducer and a collection tank. The pump was connected to a frequency inverter which was calibrated for the pump using a stopwatch and 
bucket method. The test section was a stainless steel tube of $3.86 \mathrm{~mm}$ inner diameter, $6.35 \mathrm{~mm}$ outer diameter, $1.245 \mathrm{~mm}$ thickness, and $990.6 \mathrm{~mm}$ length. Uniform heat flux was applied to the test section using a flexible heating tape (OMEGA Engg. FGS101-040). Power was supplied to the heater using a DC power (Agilent Technologies: 6655A) supply. To reduce heat loss and to ensure constant heat flux condition, the entire test section was insulated with fiberglass insulation. Five holes were drilled on the outer surface of the test sectionup to half width of the tube thickness at $203 \mathrm{~mm}$ apart fromeach other, where five K-type thermocouples were mounted. Two more K-type thermocouples were inserted at the inlet and outlet of the test section (thermocouples were placed at the center of the tube exposed directly to the liquid). A differential pressure transducer was connected between the inlet and outlet of the test section to measure the pressure drop. All thermocouples and pressure transducer were connected to a National Instrument (NI) data acquisition system cDAQ-9178 via a temperature card NI 9211 and pressure card NI 9203 which were interfaced with a computer. LabView ${ }^{\circledR}$ program.

\subsubsection{Experimental procedure}

To perform the experiment with IL, the whole test loop was washed out by DI water and the pump was run with air for several hours to remove all water bubbles from the test loop. After putting the IL in the tank the pump was set to run at a desired flow rate and set the desired power input from the DC power supply. The test section was allowed to reach steady state before the temperature data were recorded, which was monitored by the LabView software. After recording the data, the flow rate was increasedto the next pump flow rate. The same procedure was repeated up to the maximum allowable flow rate of the pump.

\subsubsection{Data processing}

Heat flux $\left(q^{\prime \prime}\right)$ was calculated from input power $(Q)$ of the heater and heating surface area $\left(A_{h}\right)$ using the following equation:

$q^{\prime \prime}=\frac{Q}{A_{h}}=\frac{V I}{\pi D_{o} L}$

where, $V$ and $I$ are the input voltage and current respectively, $D_{o}$ is the outer diameter of tube, and $L$ is the heating length. 
Local heat transfer coefficient at an axial distance $x$, along the test section, $h(x)$, was calculated using the equation:

$h(x)=\frac{q^{\prime \prime}}{T_{w}^{\prime}(x)-T_{f}(x)}$

where, $T_{w}^{\prime}(x)$ and $T_{f}(x)$ are the local temperatures of the inner surfaceand liquid respectively.

The inner surface temperature was calculated using steady state one-dimensional heat conduction equation with constant heat flux boundary condition for which the governing equation is:

$\frac{1}{r} \frac{d}{d r}\left(r \frac{d T}{d r}\right)=0$

The solution for the inner surface temperature becomes

$T_{w}^{\prime}(x)=T_{w}(x)-\frac{Q \cdot \ln \left(r_{o} / r_{i}\right)}{2 \pi L k_{s}}$

where, $T_{w}(x)$ is the local temperature of outer surface as measured by the thermocouples, $r_{o}$ and $r_{i}$ are the outer and inner radius of the test tube respectively, and $k_{s}$ is the thermal conductivity of stainless steel.

Local temperature of the liquid was calculated using the energy balance relation:

$T_{f}(x)=T_{f i}+\frac{Q}{\rho C_{p} V^{\prime}} \frac{x}{L}$

where, $T_{f i}$ is the liquid inlet temperature of the test section, $C_{p}$ is the heat capacity of the liquid, and $V^{\prime}$ is the volumetric flow rate.

\subsection{Uncertainty and error analysis}

The measurement uncertainty of thermocouples, voltage, and current are $\pm 0.18^{\circ} \mathrm{C}, \pm 0.01 \mathrm{~V}$, and $\pm 0.001 \mathrm{~A}$. A systematic uncertainty analysis was performed using standard Kline and McClintock method [28].

$W_{p}=\sqrt{\sum_{i=1}^{n}\left(\frac{\partial p}{\partial a_{i}} w_{i}\right)^{2}}$ 
where, $W_{p}$ is the total uncertainty of calculated parameter, $p$, and $a_{i}$ variables of functional dependence, and $w_{i}$ is the uncertainty of the independent variables. Input power uncertainty was calculated to be $\pm 0.15 \%$, heat transfer coefficient has an uncertainty of $\pm 0.89 \%$. Since the dimensionless numbers are the functions of numerous measured quantities and physical properties, therefore the uncertainty will propagate. The maximum uncertainties associated with the Nusselt number and Reynolds number were calculated to be $\pm 3.48 \%$ and $\pm 4.1 \%$ respectively.

\section{RESULTS AND DISCUSSION}

\subsection{Density of $\left[\mathbf{N}_{4111}\right]\left[\mathbf{N T f}_{2}\right]$}

Fig. 2 shows the density of $\left[\mathrm{N}_{4111}\right]\left[\mathrm{NTf}_{2}\right]$ as a function of temperature, here the density was measured from 283-343K. As can be seen from the Fig.2, density decreases marginally with temperature. The measured density was presents as a function of temperature with the following linear correlation with the regression value of $R^{2}=0.98$.

$\rho=-0.00084 T+1.62904 \pm 0.0084$

where, $T$ is temperature in Kelvin unit and $\rho$ is density in $\mathrm{g} / \mathrm{cm}^{3}$. Present measurements were compared with the experimentally measured previously published data [25-27] and it is clear from Fig. 2 that the present data correlates well with the previously published data.

\subsection{Viscosity of $\left[\mathbf{N}_{4111}\right]\left[\mathbf{N T f}_{2}\right]$}

Fig. 3(a) shows the shear rate as a function of shear stress of $\left[\mathrm{N}_{4111}\right]\left[\mathrm{NTf}_{2}\right]$ IL at $30^{\circ} \mathrm{C}$. The linear behavior of shear stress and shear rate confirms the Newtonian behavior of IL. Fig. 3(b) shows the shear viscosity as a function of shear rate at two different temperatures, which indicate the strong temperature effect on the viscosity of IL. The same indication is as clear from the Fig. 4, where viscosity of IL is presented as a function of temperature within 293-363K and the viscosity depends on temperature with an exponential manner, which is:

$\mu=\exp \left[-7.5969+3.5898 \times \frac{1000}{T}\right]$

where, $T$ is temperature in Kelvin unit and $\mu$ is viscosity in centipoise (cP). The exponential relation is consistent with the mostly used viscosity relation by $\mathrm{R}$. B. Bird et al. [29]. The 
present measured viscosity data correlates well with the previously published data [26-27], which was clear from Fig. 4.

\subsection{Heat capacity of $\left[\mathrm{N}_{4111}\right]\left[\mathrm{NTf}_{2}\right]$}

Heat capacity of $\left[\mathrm{N}_{4111}\right]\left[\mathrm{NTf}_{2}\right]$ as a function of temperature is presented in Fig. 5; within the measured temperature range of $298-618 \mathrm{~K}$ the heat capacity increases almost linearly with temperature and varies from 638.55-888.26 J/mol.K. There was only one heat capacity of $\left[\mathrm{N}_{4111}\right]\left[\mathrm{NTf}_{2}\right]$ measurement published result available in literature [27], which is shown in Fig.5, they have $\pm 6 \%$ variation for each data point. The main difference from the present measurement is the temperature range; previous research studied heat capacity between $343-450 \mathrm{~K}$. The present measurement included much higher temperature range, which is very important for solar thermal applications. The present data shows higher heat capacity comparedwith the literature, but overlapping within the standard deviation values. The same scattered heat capacity data were reported for other IL and in a recent study report by IUPAC mentioned that such variation in heat capacity measurement is typical [30].

\subsection{Thermal conductivity of $\left[\mathrm{N}_{4111}\right]\left[\mathrm{NTf}_{2}\right]$}

Fig. 6 shows the thermal conductivity of $\left[\mathrm{N}_{4111}\right]\left[\mathrm{NTf}_{2}\right]$ as a function of temperature within the measured temperature range of $283-343 \mathrm{~K}$ and the thermal conductivity varied from $0.124-0.121$ $\mathrm{W} / \mathrm{m} . \mathrm{K}$ which indicates that $\left[\mathrm{N}_{4111}\right]\left[\mathrm{NTf}_{2}\right]$ has a relatively lower thermal conductivity and has thermal conductivity of approximately $20 \%$ that of DI-water at room temperature. From Fig. 6 it is also clear that within the studied temperature thermal conductivity of $\left[\mathrm{N}_{4111}\right]\left[\mathrm{NTf}_{2}\right]$ decreases only slightly with temperature implying that thermal conductivity has a very low temperature effect. The temperature dependent thermal conductivity can be represented by the linear equation:

$k_{f}=-4 \times 10^{-5} T+0.134$

where, $k_{f}$ is the thermal conductivity of $\mathrm{IL} \mathrm{W} \cdot \mathrm{m}^{-1} \mathrm{~K}^{-1}$ unit and $T$ is the temperature in Kelvin unit. Similar temperature effects were reported inpreviously published results for different imidazolium and pyrrolidinium based ILs using the same method and same device [31-33] and also with same transient hot wire method, but using other experimental setup [8,34]. There was 
only one previous study [27] which reported the thermal conductivity of $\left[\mathrm{N}_{4111}\right]\left[\mathrm{NTf}_{2}\right]$ which is presented in Fig. 6 and agrees well with the present experimental data within the standard deviation range. The higher temperature range data investigated by the present study are very important for assessment of the thermal performance of ILs in solar thermal applications.

\subsection{Convective Heat Transfer Coefficient}

\subsubsection{Convective heattransfer coefficient of DI water}

Before performing the experiments with IL, the experimental system was tested with DI water to evaluate the reliability of measurements. Fig. 7(a) and (b) shows the heat transfer behavior of DI water with the axial distance at laminar $(\operatorname{Re}<2300)$ and turbulent $(\operatorname{Re}>2300)$ flow region. The experimental results were compared with the well known Shah's correlation for laminar flow [35] and Gnielinski equation for turbulent flow [36] at the constant heat flux boundary conditions:

Shah's equation for laminar flow:

$$
N u(x)= \begin{cases}1.953\left(\operatorname{RePr} \frac{D}{x}\right)^{\frac{1}{3}} & \left(\operatorname{RePr} \frac{D}{x}\right) \geq 33.3 \\ 4.364+0.0722 \operatorname{RePr} \frac{D}{x} & \left(\operatorname{RePr} \frac{D}{x}\right)<33.3\end{cases}
$$

Gnielinski's equation for turbulent flow at a range of $<0.5<\operatorname{Pr}<10^{6}$ and $2300<\operatorname{Re}<$ $5 \times 10^{6}:$

$N u=\frac{\left(\frac{f}{8}\right)(R e-1000) P r}{1.07+12.7 \sqrt{\frac{f}{8}}\left(\operatorname{Pr}^{\frac{2}{3}}-1\right)}$

where, $N u(x), R e, \operatorname{Pr}$ are the Nusselt, Reynolds, and Prandtl number respectively, which were defined as

$$
N u(x)=\frac{h(x) D}{k_{f}} \quad \operatorname{Re}=\frac{\rho u D}{\mu} \quad \operatorname{Pr}=\frac{v_{f}}{\alpha}
$$

where, $h(x)$ is the local heat transfer coefficient, $D$ is the inner diameter of test section, $k_{f}$ is the thermal conductivity of fluid, $\rho$ is the fluid density, $\mu$ is the fluid viscosity, $u$ is the velocity of 
fluid, $v_{f}\left(=\frac{\mu}{\rho}\right)$ is the kinematic viscosity, $\alpha\left(=\frac{k_{f}}{\rho C_{p}}\right)$ is the thermal diffusivity, and $f$ is the friction factor, which was calculated by:

$f=\frac{1}{\left\{1.82 \log _{10}(R e)-1.64\right\}^{2}}$

All the fluid properties were evaluated at the average $\left(T_{a v}=\frac{T_{i n}+T_{o u t}}{2}\right)$ of the inlet and outlet fluid temperature of the test section. It isclear from Fig. 7(a) and 7(b) that there are reasonably good agreements between predicted and measured Nusselt number of DI water over the Reynolds number range studied for laminar and turbulent flow region.

\subsubsection{Convective heat transfer coefficient of ionic liquid}

After getting confidence with the experimental setup, forced convection experiments were performed for $\left[\mathrm{N}_{4111}\right][\mathrm{NTf} 2]$ IL under laminar and turbulent flow conditions. Fig. 8 is the typical surface and fluid temperature profile along the axial distance at two different Reynolds number. In the present study the fluid temperature was within $95-135^{\circ} \mathrm{C}$, which is also clear from the Fig. 8 and temperature increases linearly along the axial distance due to constant heat flux condition. From Fig. 8 it is also clear that the turbulent temperature profile for surface and fluid has almost constant rate increment from the beginning which was expected because in turbulent flow the entrance length is very small (hydrodynamic entry length $=x_{h} \approx$ thermal entry length $=$ $x_{t} \approx 10 D$ ), whereas in the laminar flow the hydrodynamic entrance length is, $x_{h}=0.05 R e . D$ and thermal entrance length is, $x_{t}=0.05 \operatorname{Re}$.Pr.D [37], these behaviors are also discussed in the following sections. The schematic of development of flow through a pipe in the laminar flow regime was shown in Fig. 9.

Fig. 10 (a) and (b) shows the heat transfer behavior of $\left[\mathrm{N}_{4111}\right]\left[\mathrm{NTf}_{2}\right]$ IL for different Reynolds number at laminar and turbulent flow region respectively. In laminar flow (Fig.10 (a)) for a certain Reynolds number, Nusselt number decreases along the axial distance which is because of entrance effect. Initially the thermal boundary layer thickness remains thin, gradually increases the thickness up to hydrodynamically fully develop. Whereas in turbulent flow (Fig. 10 (b)) for a certain Reynolds number, Nusselt number remain almost constant along the axial distance since for turbulent flow the entrance effect is very low compared to laminar flow. The studied laminar 
Reynolds number ranges the hydrodynamic entrance length in terms of diameter varies from $x=25 D-113 D$. But the thermal entrance length in terms of diameter varies from $x=$ $3000 D-13560 D$ which means the experiment was hydrodynamic developed and not thermally developed which was clear from the Fig. 10(a). At a certain point both for laminar and turbulent flow conditions Nusselt number increases with Reynolds number which were clear from Fig. 11(a) and Fig. 11(b). This is because as a result of the higher Reynolds number the boundary layer thickness becomes thinner, which increases the heat transfer coefficient. The experimental results were also compared with the predicted Shah's equation for laminar flow and Gnielinski equation for turbulent flow in Fig. 11(a) and Fig. 11(b) respectively. It can be seen that the experimental results are closely predicted by the well established equations for laminar and turbulent flow conditions, which is an important finding for ILs that the well established equations could be used to predict the heat transfer behavior of ILs at high temperature condition for solar thermal applications.

Fig. 12(a) and Fig. 12(b) shows the comparison of heat transfer coefficient of IL and DI water for laminar and turbulent flow conditions respectively. It is apparent that the heat transfer coefficient of IL is much lower than the DI water, this may be because of the lower thermal conductivity and higher viscosity of IL. The same lower heat transfer coefficient IL was observed by previously studied forced [38] and natural [39] convection of 1-butyl-3methylimidazolium bis $\{$ (trifluoromethyl)sulfonyl $\}$ imide, $\left[\mathrm{C}_{4} \mathrm{mim}\right]\left[\mathrm{NTf}_{2}\right]$ IL. The previous forced convection study was performed in laminar flow region at maximum Reynolds number 120 and lower operating temperature. In solar thermal collector,the operating temperature of the fluid is high and flow will be expected to be in the turbulent region.

\section{CONCLUSIONS}

Forced convection experiments were performed with N-butyl-N,N,Ntrimetylammoniumbis(trifluormethylsulfonyl)imide $\left(\left[\mathrm{N}_{4111}\right]\left[\mathrm{NTf}_{2}\right]\right)$ ionic liquid under laminar and turbulent flow conditions. In addition to characterize the heat transfer behavior, thermophysical properties of IL were measured experimentally.

The density of ionic liquid varies from $1.39-1.34 \mathrm{~g} / \mathrm{cm}^{3}$ over the measured temperature (283$343 \mathrm{~K})$ range. Thermal conductivity varies from $0.124-0.121 \mathrm{~W} / \mathrm{m} . \mathrm{K}$ within the measured 
temperature (283-343K) range which was much lower than the thermal conductivity of water. The rheological behavior shows strong temperature effect on the viscosity of ionic liquid and sharply decreases with temperature. Heat capacity varies almost linearly from 638.55-888.261 $\mathrm{J} / \mathrm{mol} . \mathrm{K}$ within the measured temperature (298-618K) range.

Laminar convection behavior shows hydrodynamically developed, but not thermally developed flow due to high viscosity and low thermal conductivity of ionic liquid. In turbulent conditions the flow was fully developed because entry length is small and there was no entrance effect observed. Heat transfer behavior correlates well with the Shah's and Gnielinski's equations for laminar and turbulent flow conditions respectively. The finding of this experiment is useful for the assessment of ionic liquid in solar thermal collector for high temperature applications and heat transfer behavior could be predicted by the well established equations.

\section{ACKNOWLEDGEMENT}

The financial support for this research is from Department of Energy (DOE) Solar Energy Technology Program. Savannah River National Laboratory is operated by Savannah River Nuclear Solutions. This document was prepared in conjunction with work accomplished under Contract No. DEAC09-08SR22470 with the U.S. Department of Energy. 


\section{REFERENCES}

[1] M. Bosatra, F. Fazi, P. F. Lionetto, L.Travagnin,Utility Scale PV and CSP Solar Power Plants Performance, Impact on the Territory and Interaction with the Grid.Foster Wheeler ItalianaCorsico (Milan- ITALY) (2010) June 8-10.

[2] M. Eck, K. Hennecke, Heat transfer fluids for future parabolic trough solar thermal Power plants, Proceedings of ISES World Congress 5 (2009)1806-1812.

[3] B.Wu, R.G.Reddy, R. D.Rogers, Novel Ionic Liquid Thermal Storage for Solar Thermal Electric Power System. Proceedings of Solar Forum, Solar Energy: The Power to Choose (2001) April 21-25, Washington, DC.

[4] L. Moens, D.M.Blake, D. L. Rudnicki, M.J. Hale, Advanced Thermal Storage Fluids for Solar Parabolic Trough Systems, ASME Journal of Solar Energy Engineering 125 (2003).

[5] D.M.Blake, L. Moens, M.J. Hale, H. Price, D. Kearney, U. Herrmann, New Heat Transfer and Storage Fluids for Parabolic Trough Solar Thermal Electric Plants. Proceedings of the 11th Solar PACES International Symposium On concentrating Solar Power and Chemical Energy Technologies (2002) September 4-6, Zurich, Switzerland.

[6] J. F.Wishart, Energy applications of ionic liquids, Energy Environmental Science2(9) (2009) 956-961.

[7] I.Perissia, U. Bardia, S. Caporalia, A. Fossatia, A. Lavacchia, Ionic liquids as diathermic fluids for solar trough collectors' technology:A corrosion study,Solar Energy Materials \& Solar Cells 92(2008) 510-517.

[8] M.E.VanValkenburg, R.L.Vaughn, M. Williams, J.S.Wilkes, Thermochemistry of ionic liquid heat-transfer fluids, Thermochimica Acta 425(2005) 181-188.

[9] R.D.Rogers, K.R.Seddon, Ionic liquids-solvents of the future? Science 302(2003) 792-793.

[10] M. Kosmulski, J. Gustafsson, J.B.Rosenholm, Thermal stability of low temperature ionic liquids revisited, Thermochimica Acta 412(2004) 47-53.

[11] Y.U. Paulechka, D. H.Zaitsau, G.J.Kabo, A.A.Strechan, Vapor pressure and thermal stability of ionic liquid 1-butyl-3-methylimidazolium Bis(trifluoromethylsulfonyl)amide, Thermochimica Acta 439 (2005)158-160.

[12] F. Endres, S. Z. E. Abedin, Air and water stable ionic liquids in physical chemistry, Physical Chemistry Chemical Physics 8(2006)2101-2116. 
[13] H.L.Ngo, K. LeCompte, L. Hargens, A.B.McEwen, Thermal properties of imidazolium ionic liquids, Thermochimica Acta 357-358 (2000), 97-102.

[14] T. Tsuda, T. Hussey,Electrochemical Applications of Room-Temperature Ionic Liquids, The Electrochemical Society Interface 16(2007) 42-49.

[15] M. Smiglak, W. M. Reichert, J. D.Holbrey, J.S.Wilkes, L. Sun, J.S.Thrasher, K. Kirichenko, S. Singh, A.R.Katritzky, R. D.Rogers, Combustible ionic liquids by design: is laboratory safety another ionic liquid myth? Chemical Communication. 24 (2006) 2554-2556.

[16] W-J.Li, B-X. Han, R-T. Tao, Z-F. Zhang, J-L. Zhang, Measurement and Correlation of the Ionic Conductivity of Ionic Liquid-Molecular Solvent Solutions,Chinese Journal of Chemistry 25(2007)1349-1356.

[17] T.Welton, Room-Temperature Ionic Liquids. Solvents for Synthesis and Catalysis, Chemical Reviews99(1999) 2071-2083.

[18] I. Perissi, U. Bardi, S. Caporali, A. Lavacchi, High temperature corrosion properties of ionic liquids, Corrosion Science 48(2006) 2349-2362.

[19] J. Zhua, L. Baia, B. Chena,W. Fei, Thermodynamical properties of phase change materials based on ionic liquids, Chemical Engineering Journal 147(2009) 58-62.

[20] J. An,D. Wang, Q. Luo, X. Yuan, Antimicrobial active silver nanoparticles and silver/polystyrene core-shell nanoparticles prepared in room-temperature ionic liquid, Materials Science and Engineering C 29(2009)1984-1989.

[21] A. E. Jimenez, M. D. Bermudez, Ionic Liquids as Lubricants of Titanium-Steel Contact, Tribology Letters 33(2009)111-126.

[22] H. Tokuda,S. Tsuzuki,Md. A. B. H. Susan,K. Hayamizu,M. Watanabe,How Ionic Are Room-Temperature Ionic Liquids? An Indicator of the Physicochemical Properties,Journal of Physical Chemistry B110 (2006) 19593-19600.

[23] A.Wandschneider, J.K.Lehmann, A. Heintz, Surface Tension and Density of Pure Ionic Liquids and Some Binary Mixtures with 1-Propanol and 1-Butanol.Journal of Chemical Engineering Data 53 (2008)596-599.

[24] J. Jacquemin, P. Husson,V. Mayer, I. Cibulka, High-Pressure Volumetric Properties of Imidazolium-Based Ionic Liquids: Effectof the Anion, Journal of Chemical Engineering Data 52(2007)2204-2211. 
[25] P. Kilaru, G.A.Baker, P. Scovazzo, Density and Surface Tension Measurements of Imidazolium-, QuaternaryPhosphonium-, and Ammonium-Based Room-Temperature Ionic Liquids:Data and Correlations,Journal of Chemical Engineering Data52(2007)2306-2314.

[26] J.Jacquemin, P.Husson, A. A. H. Padua, V.Majer, Density and viscosity of several pure and water-saturated ionic liquids, Green Chemistry8 (2006)172-180.

[27] H. Liu, E. Maginn,A.E.Visser, N. J.Bridges, E.B.Fox, Thermal and Transport Properties of Six Ionic Liquids:An Experimental and Molecular Dynamics Study,Industrial \& Engineering Chemistry Research51 (21)(2012)7242-7254.

[28] S.J.Kline, F.A.McClintock, Describing Uncertainties in Single Sample Experiments, Mechanical Engineering (1953)3-8.

[29] R.B. Bird, W.E. Stewart, E.N. Lightfoot, Transport Phenomena, second ed. John Wiley \& Sons Inc., (2002) 29-31.

[30] R.D. Chirico, V. Diky, J. W.Magee, M. Frenkel, K. N.Marsh, Thermodynamic and thermophysicalproperties of the reference ionic liquid:1-hexyl-3-methylimidazoliumbis [(trifluoromethyl)sulfonyl]amide(including mixtures),Part 2.Critical evaluation andrecommended property values(IUPAC Technical Report),Pure and Applied Chemistry 81(2009)791-828.

[31] R. Ge, C. Hardacre, P. Nancarrow, D.W.Rooney, Thermal Conductivities of Ionic Liquids over the Temperature Range from 293 Kto 353 K.Journal of Chemical Engineering Data, 52(2007)1819-1823.

[32] C. A.Nieto de Castro, M. J. V.Lourenco, A. P. C.Ribeiro, E.Langa,S. I. C.Vieira, Thermal Properties of Ionic Liquids and IoNanofluids of Imidazolium andPyrrolidinium Liquids,Journal of Chemical Engineering Data 55(2010)653-661.

[33] T. C. Paul, AKM M. Morshed, E.B.Fox, A. Visser, N. Bridges, J.A.Khan, Experimental Investigation of Natural Convection Heat Transfer of an Ionic Liquid in a Rectangular Enclosure Heated from Below, Proceedings of the International Mechanical Engineering Congress and Exposition IMECE (2011) November 11-17, Denver, Colorado, USA.

[34] D. Rooney, J. Jacquemin, R. Gardas, Thermophysical Properties of Ionic Liquids,Topics In Current Chemistry 290(2010) 185-212.

[35] R. K.Shah, Thermal entry length solutions for the circular tube and parallel plates, Proceedings of the $3^{\text {rd }}$ National Heat and Mass Transfer Conference (1975) Indian Institute of Technology, Bomby. 
[36] V.Gnielinski, New equations for heat and mass transfer in the turbulent flow in pipes and channels,International Chemical Engineering16(1979) 359-368.

[37] A. Bejan, Convective Heat Transfer. $3^{\text {rd }}$ Edition (2004) by John Wiley \& Sons, Inc., Hoboken, New Jersey.

[38] H. Chen, Y. He, J. Zhu,H. Alias, Y. Ding, P. Nancarrow, C. Hardacre, D. Rooney, C. Tan, Rheological and heat transfer behaviour of the ionic liquid, $\left[\mathrm{C}_{4} \mathrm{mim}\right]\left[\mathrm{NTf}_{2}\right]$, International Journal of Heat and Fluid Flow 29(2008)149-155.

[39] T. C. Paul, AKM M. Morshed, E.B.Fox, A. Visser, N. Bridges, J.A.Khan, Buoyancy driven heat transfer behavior of $\left[\mathrm{C}_{4} \mathrm{mim}\right]\left[\mathrm{NTf}_{2}\right]$ ionic liquid: An experimentalstudy, Applied Thermal Engineering 66 (1-2)(2014) 534-540. 


\section{List of Figures:}

Figure 1: Schematic of forced convection study loop

Figure 2: Temperature dependent density of $\left[\mathrm{N}_{4111}\right]\left[\mathrm{NTf}_{2}\right]$

Figure 3(a): Shear rate as a function of shear stress of $\left[\mathrm{N}_{4111}\right]\left[\mathrm{NTf}_{2}\right]$ at $30^{\circ} \mathrm{C}$

Figure 3(b): Viscosity as a function of shear rate at two different temperatures

Figure 4: Viscosity of $\left[\mathrm{N}_{4111}\right]\left[\mathrm{NTf}_{2}\right]$ as a function of temperature

Figure 5: Heat capacity of $\left[\mathrm{N}_{4111}\right]\left[\mathrm{NTf}_{2}\right]$ as a function of temperature

Figure 6: Thermal conductivity of $\left[\mathrm{N}_{4111}\right]\left[\mathrm{NTf}_{2}\right]$ as a function of temperature

Figure 7: Comparison of the measurements with the (a) Shah's equation for laminar flow and (b) Gnielinski's equation for turbulent flow of DI water

Figure 8: Typical temperature profile along the test section

Figure 9: Schematic of development of boundary layer in a pipe flow in laminar flow regime

Figure 10: Heat transfer behavior of $\left[\mathrm{N}_{4111}\right]\left[\mathrm{NTf}_{2}\right]$ (a) laminar (b) turbulent flow condition

Figure 11: Experimental results and comparison with Shah's equation and Gnielinski equation for (a) laminar and (b) turbulent flow region respectively

Figure 12: Heat transfer coefficient of ionic liquid and water as a function of axial distance; (a) laminar flow, (b) turbulent flow 
Figure 1:

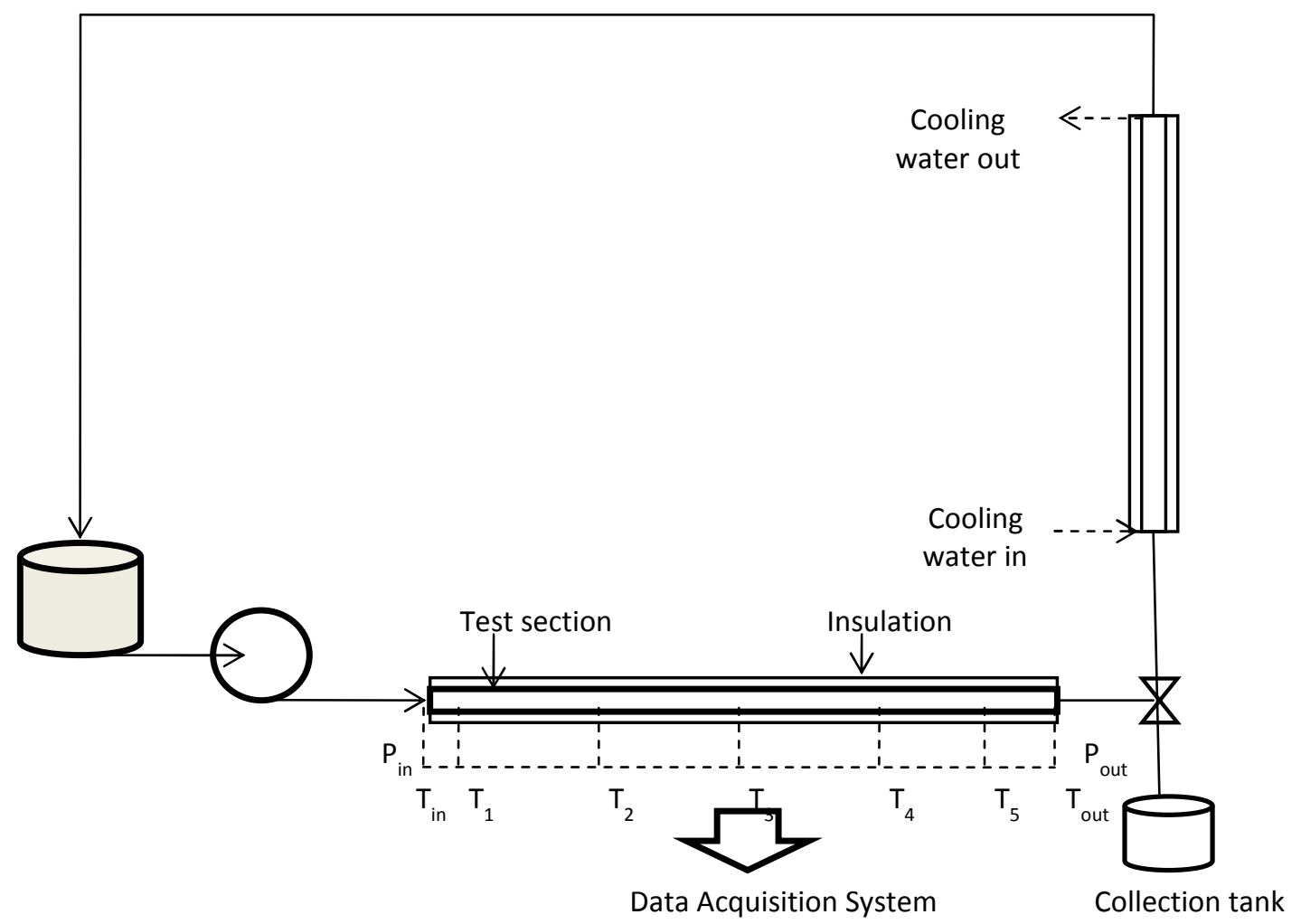


Figure 2:

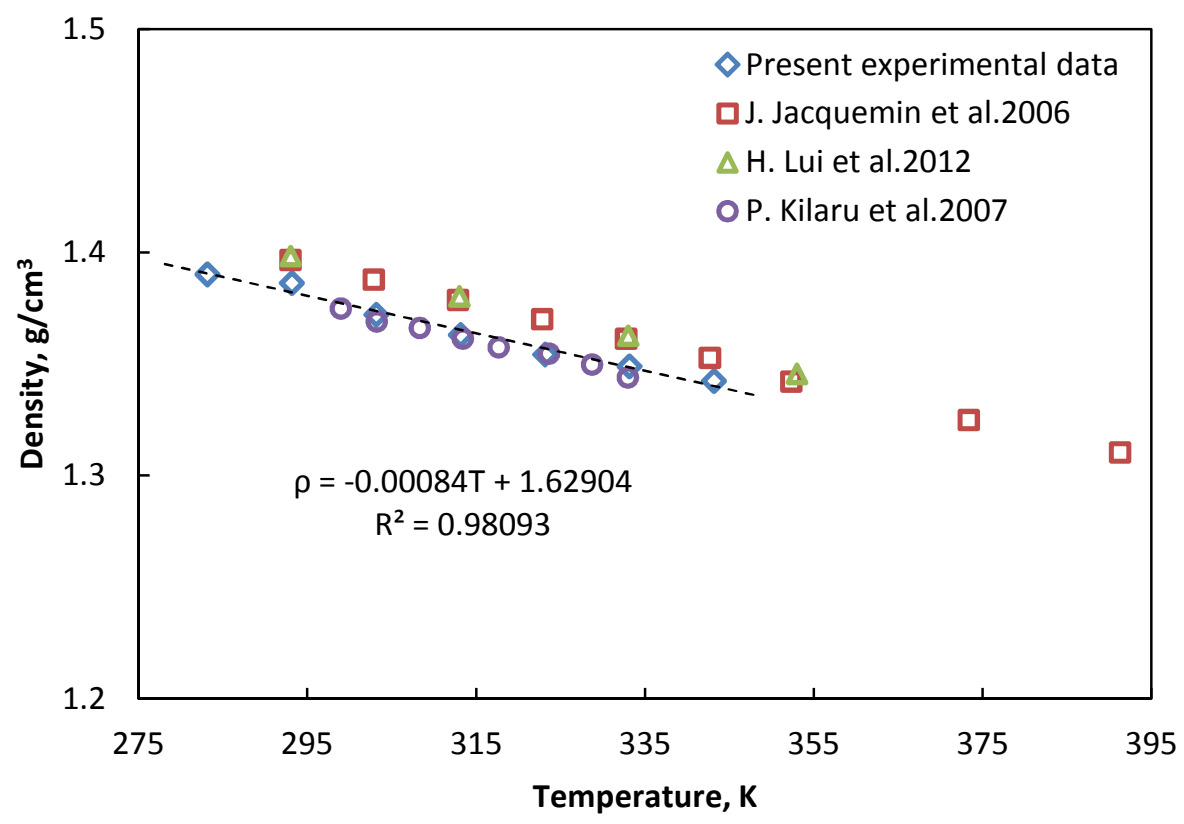


Figure 3(a):

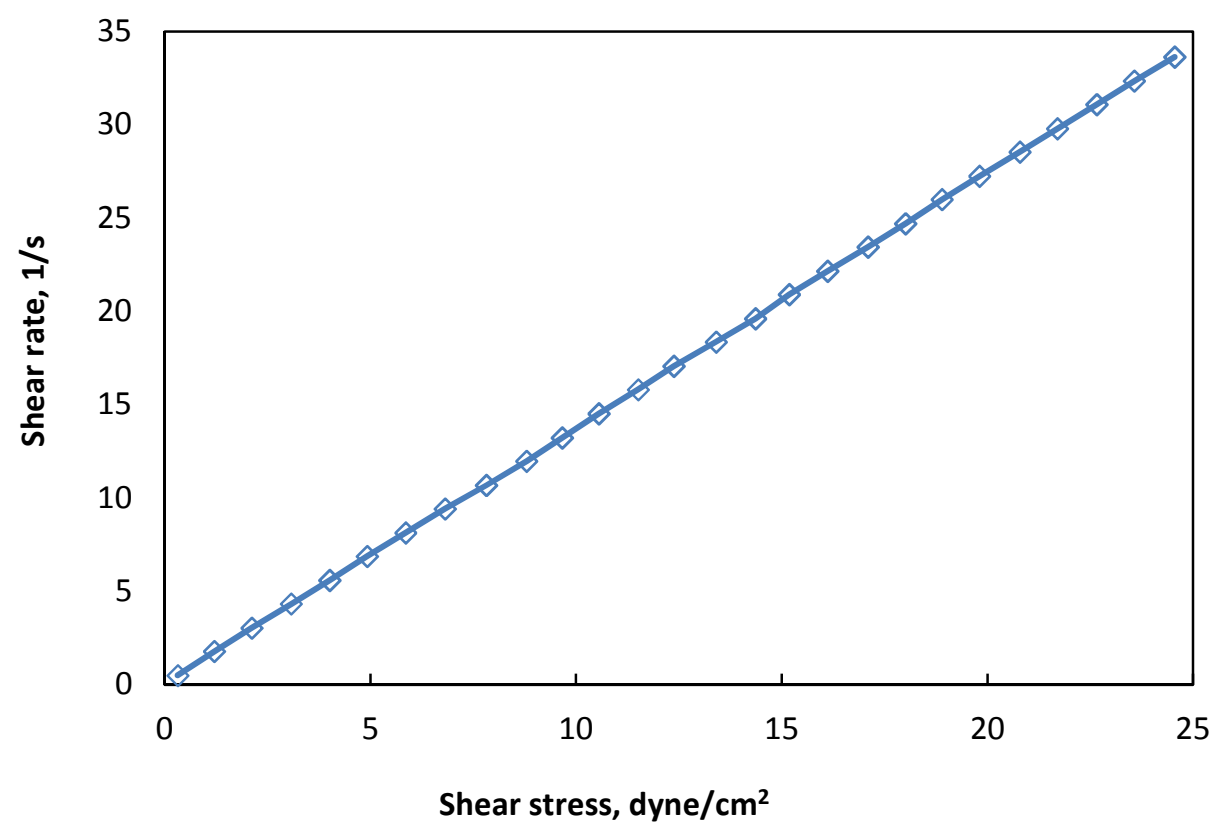

Figure 3(b):

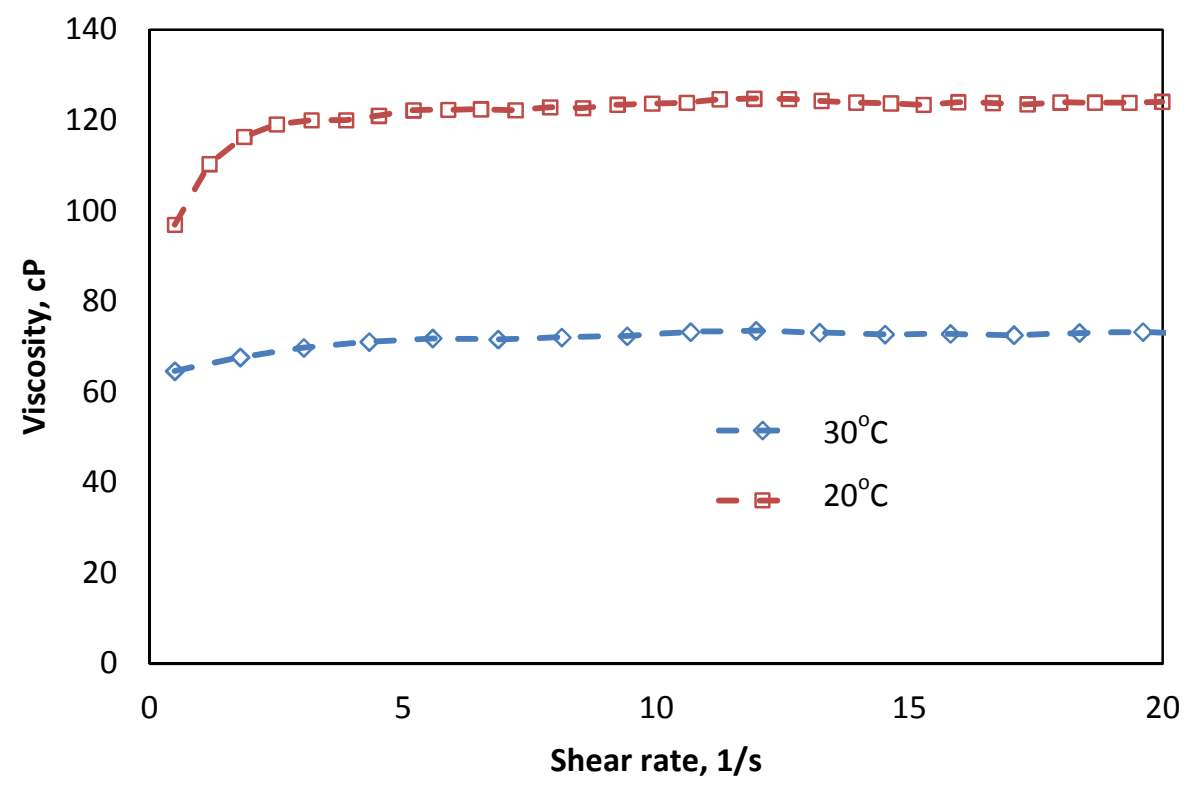


Figure 4:

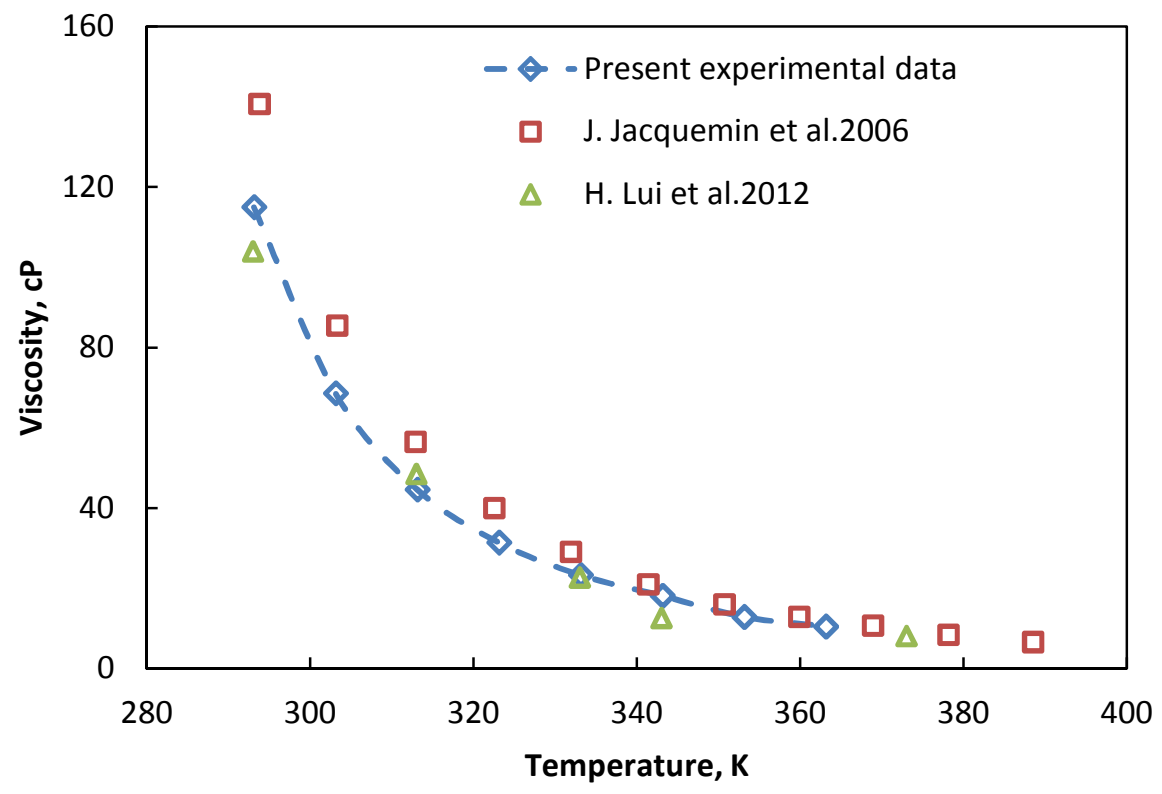


Figure 5:

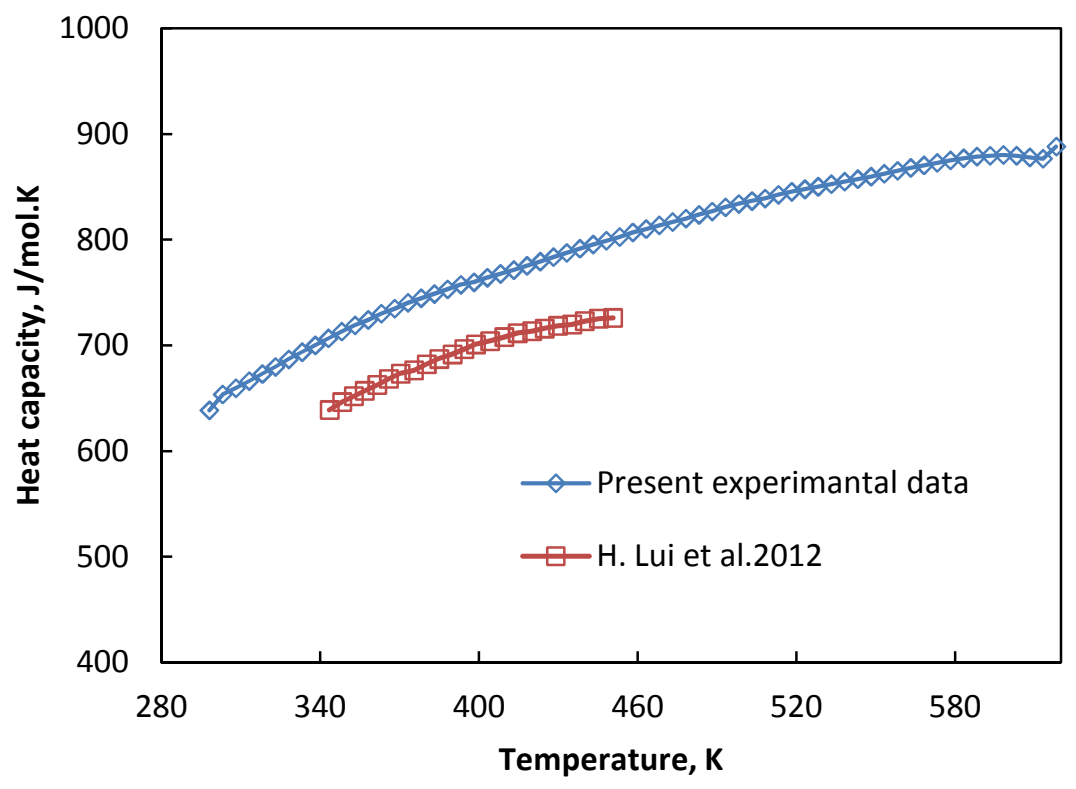


Figure 6:

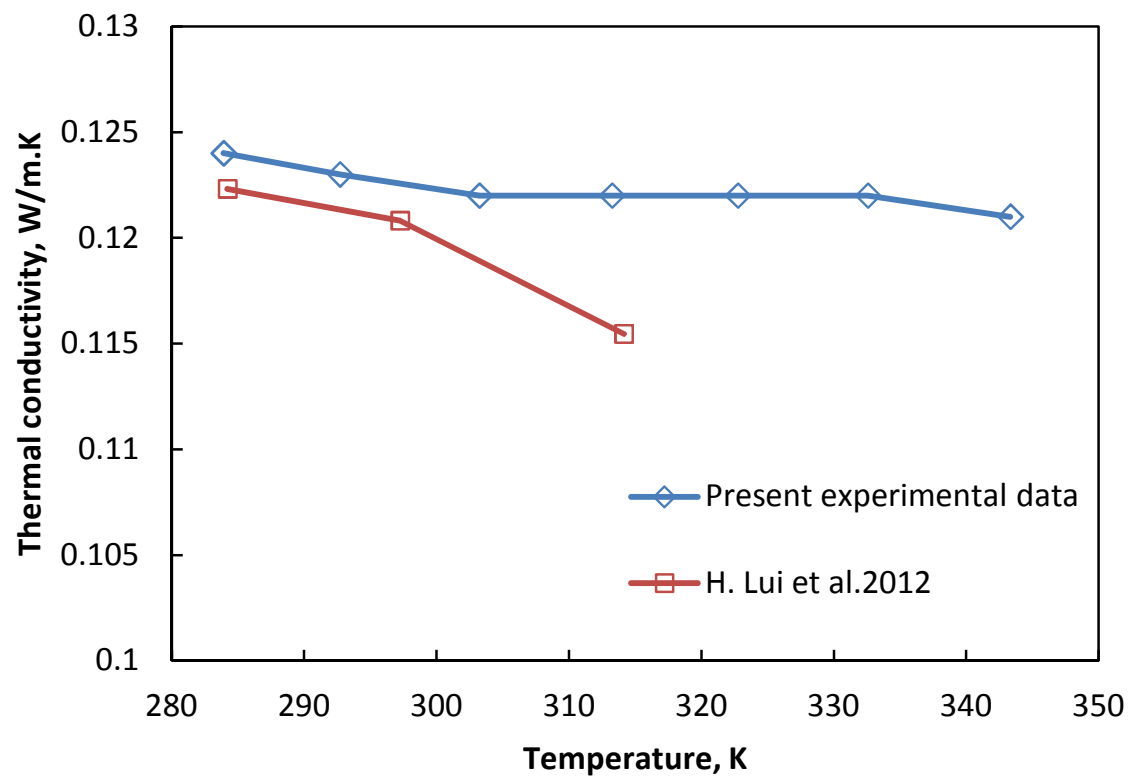


Figure 7(a):

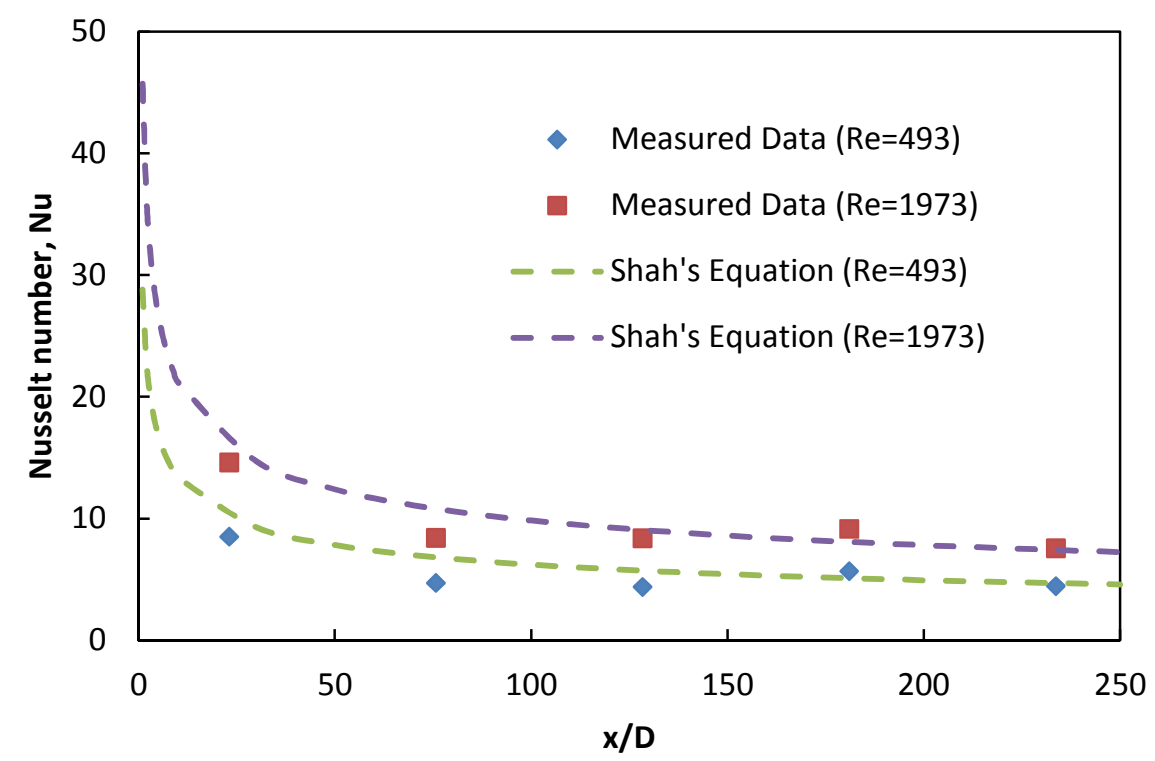

Figure 7(b):

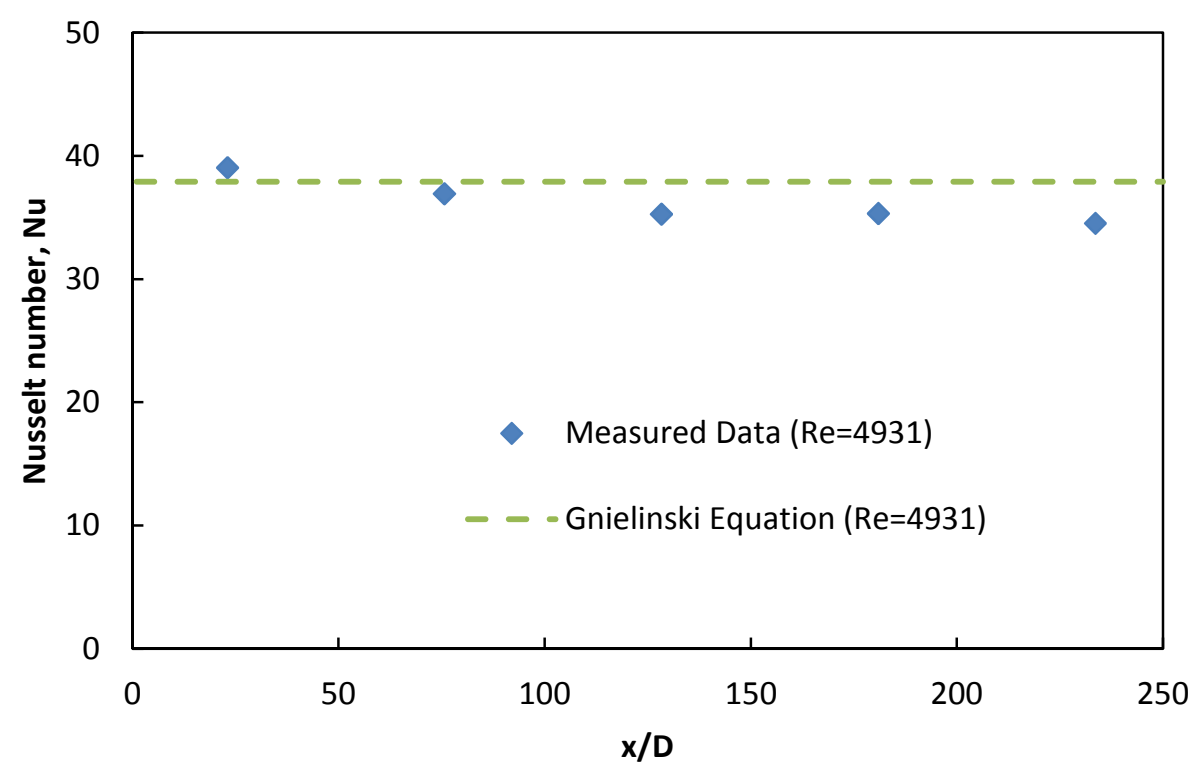

(b) 
Figure 8:

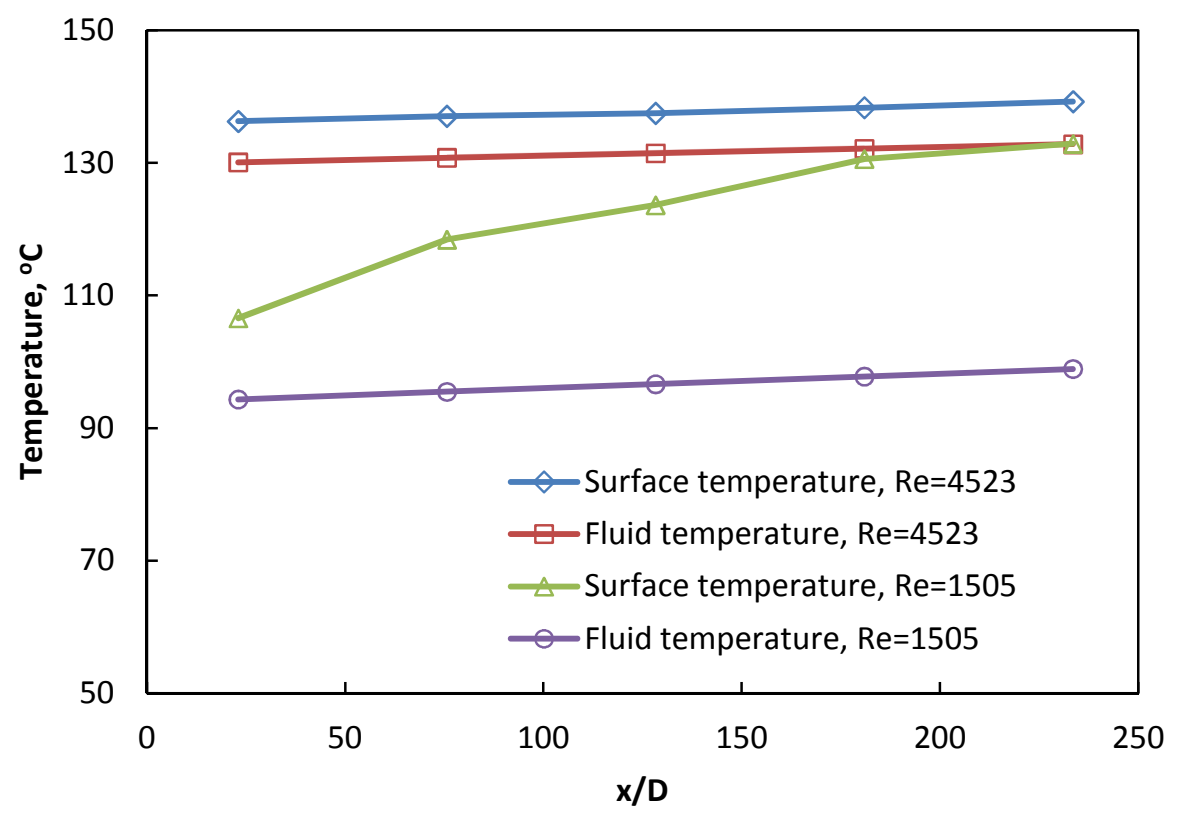


Figure 9:

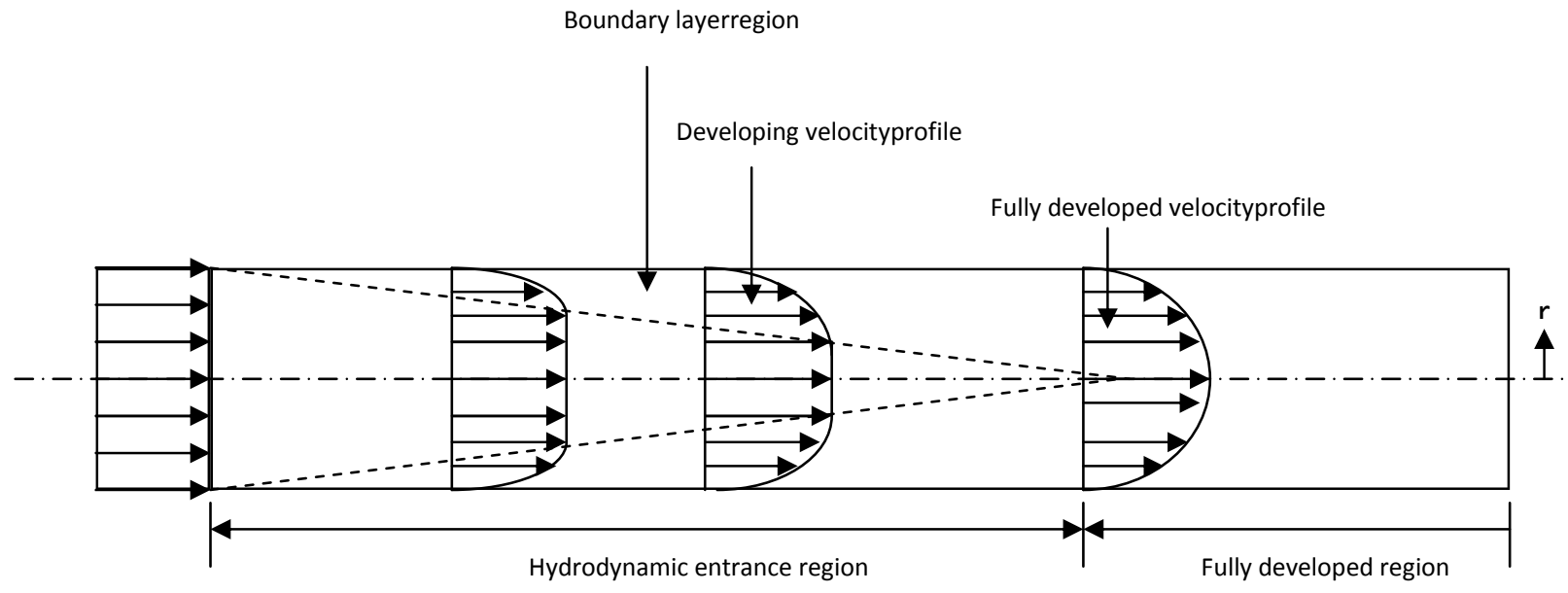


Figure 10:

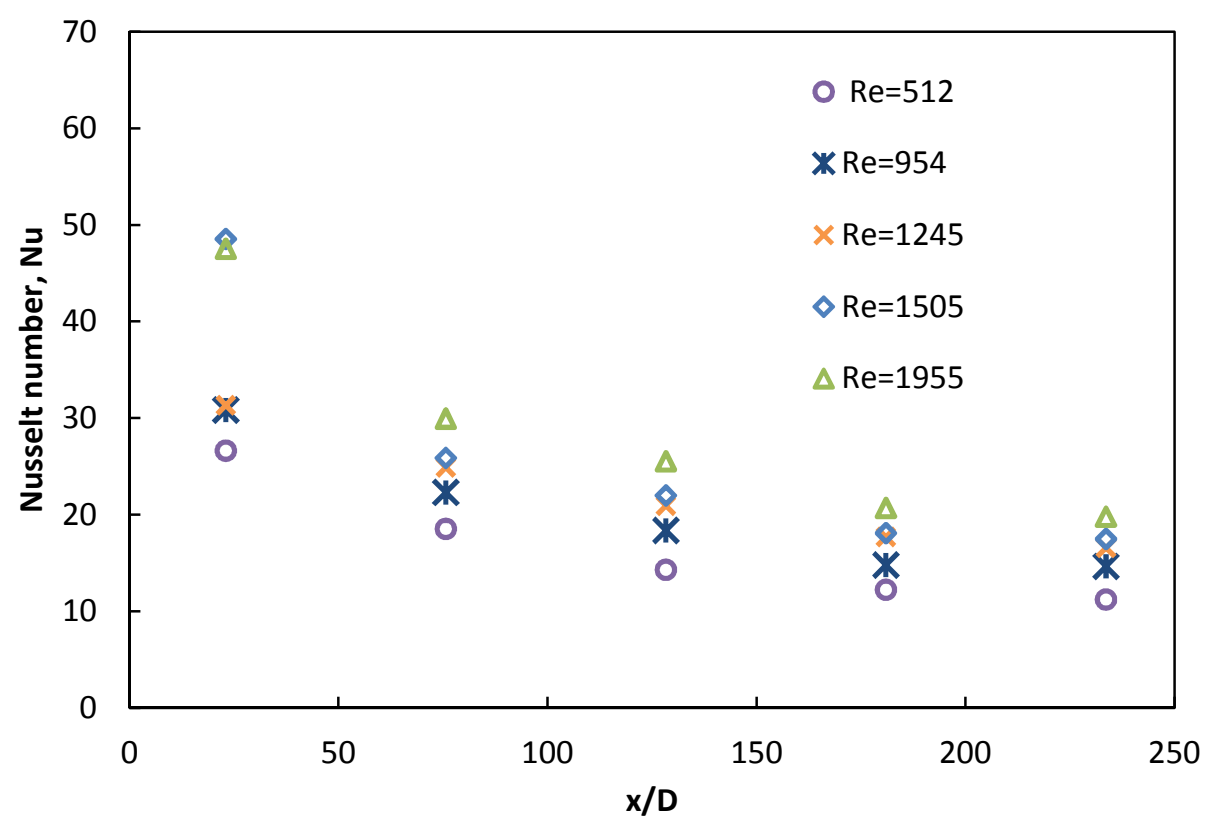

(a)

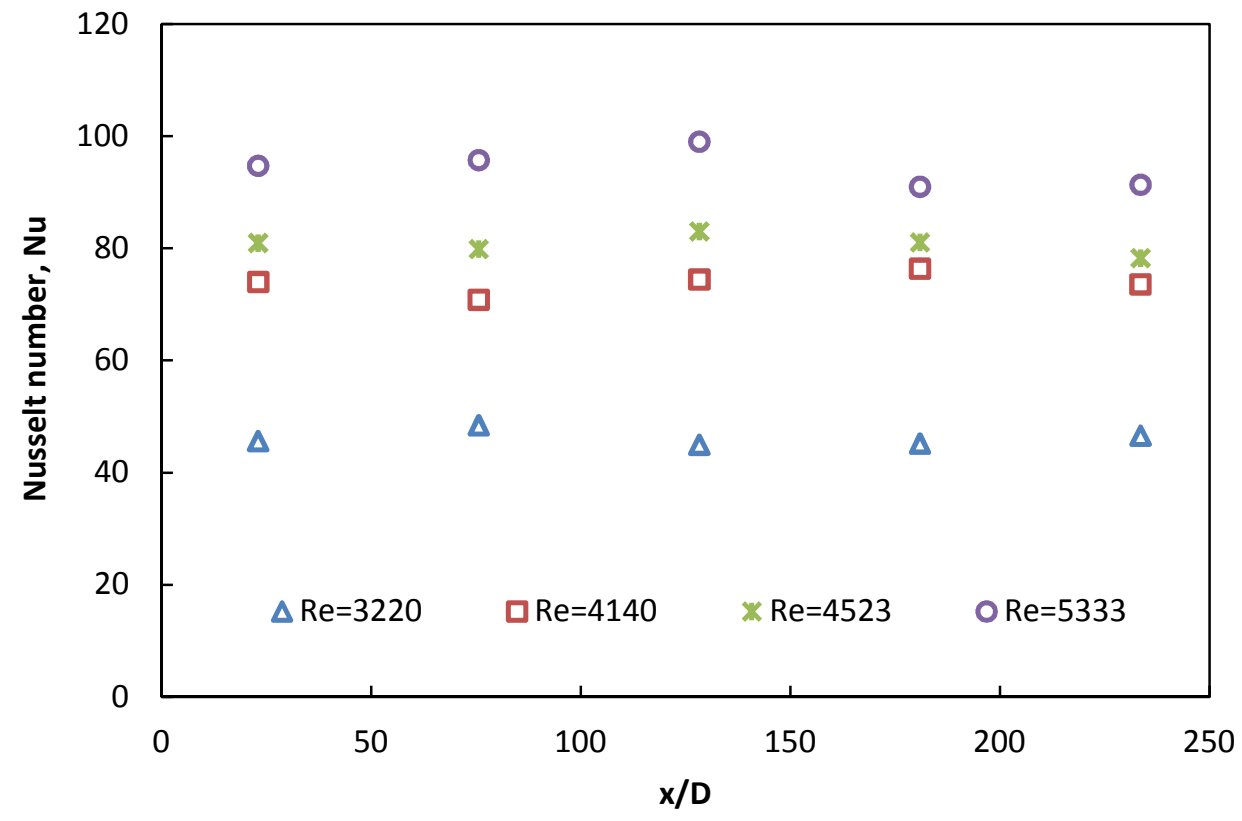

(b) 
Figure 11:

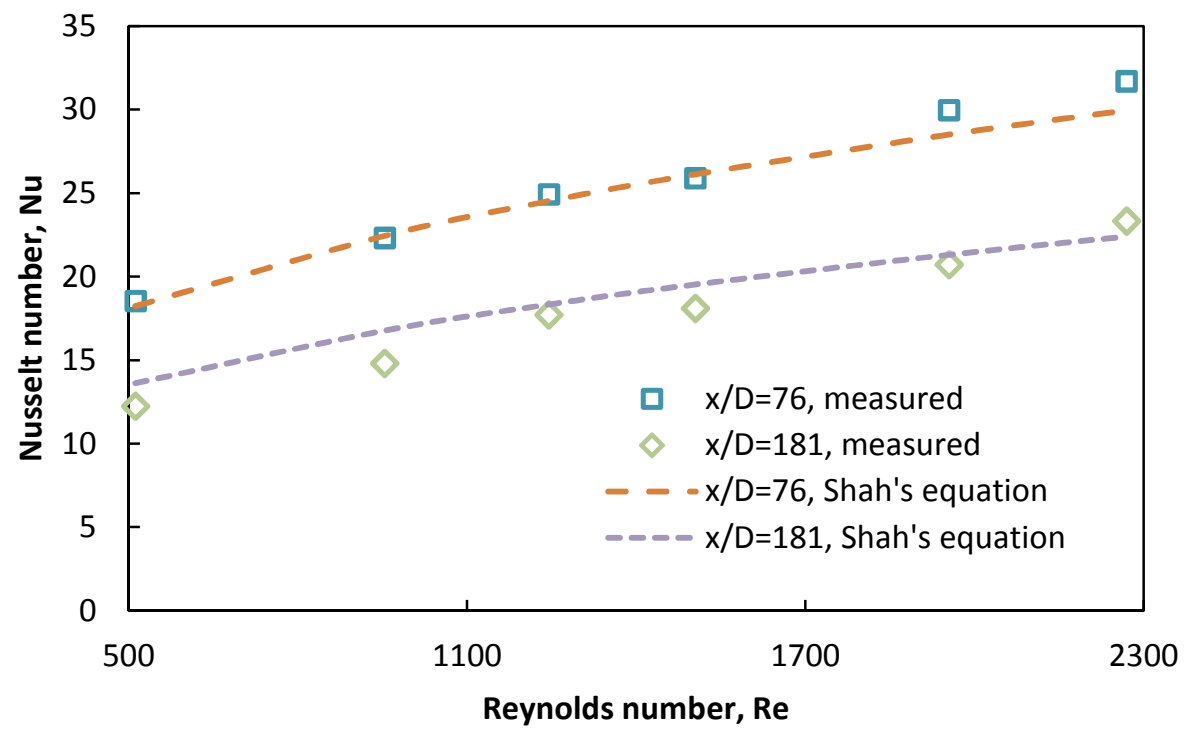

(a)

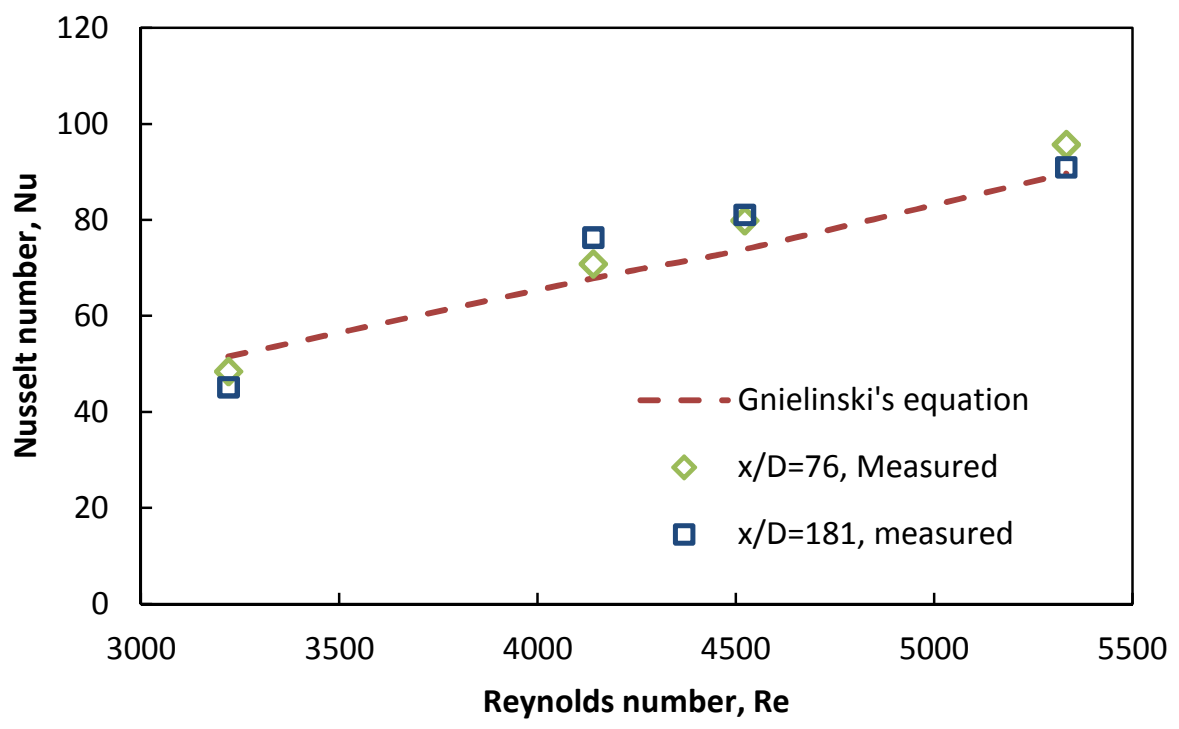

(b) 
Figure 12:

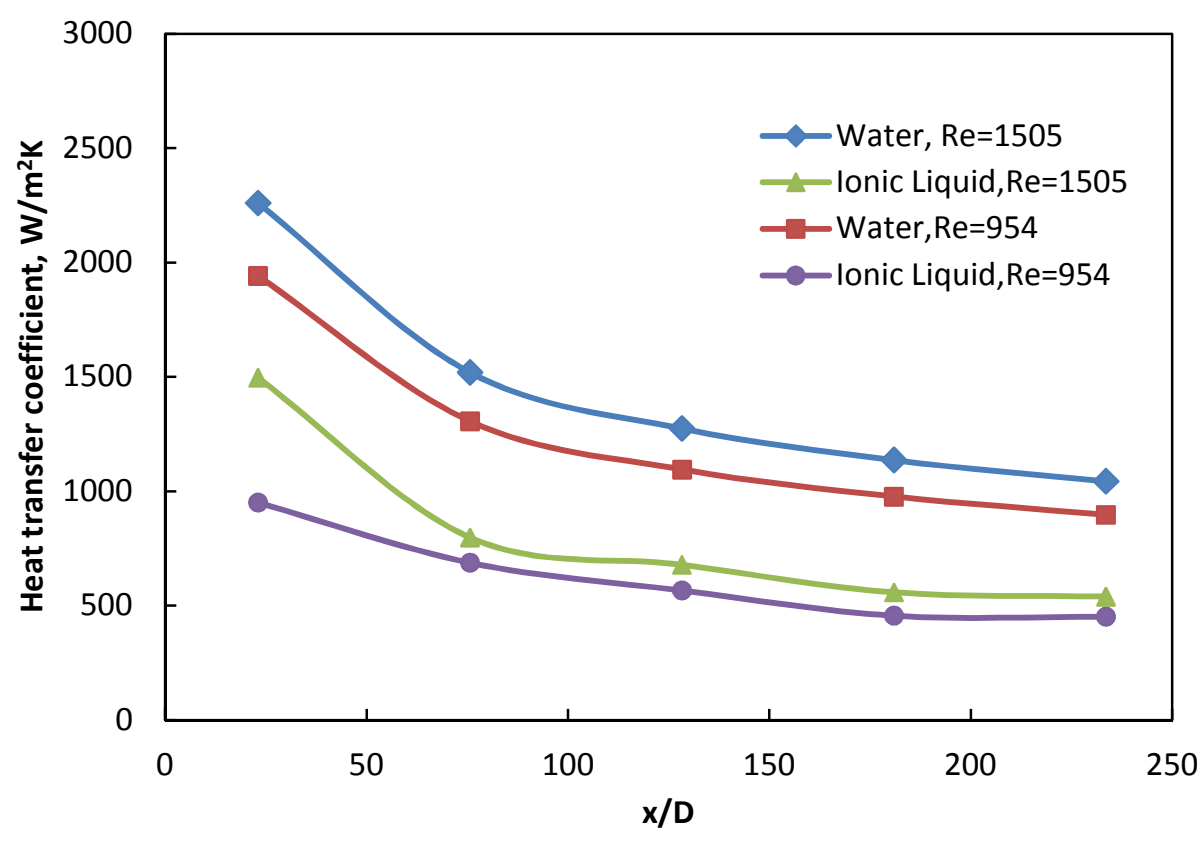

(a)

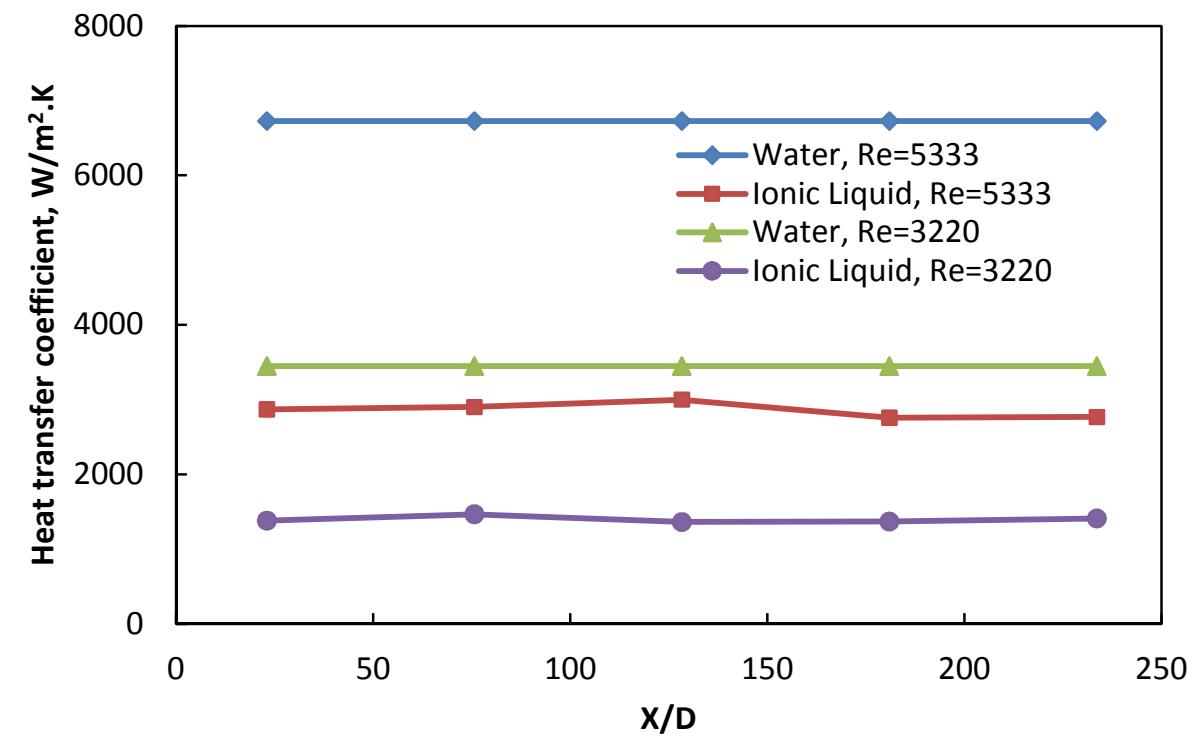

(b) 